\title{
Molecular epidemiology of cystic fibrosis mutations and haplotypes in southern Italy evaluated with an improved semiautomated robotic procedure
}

\author{
Giuseppe Castaldo, Emilia Rippa, Gianfranco Sebastio, Valeria Raia, Paola Ercolini, \\ Giorgio de Ritis, Donatello Salvatore, Francesco Salvatore
}

\begin{abstract}
We screened for 22 cystic fibrosis (CF) mutations in DNA from a first cohort of $69 \mathrm{CF}$ patients from southern Italy using a semiautomated allele specific oligonucleotide (ASO) dot blot procedure based on two multiplex PCR amplifications. Seven mutations ( $\triangle F 508, N 1303 K$, G542X, 1717-1 G $\rightarrow A, W 1282 X, 1148 T$, and R553X) identified $77 \cdot 6 \%$ of CF chromosomes. Detection reached $79.8 \%$ with the $2183 \mathrm{AA} \rightarrow \mathrm{G}$ mutation analysed with the restriction generating PCR method. Thus, we included the $2183 \mathrm{AA} \rightarrow \mathrm{G}$ mutation in the ASO protocol and set up the conditions to amplify the gene regions that include the eight mutations in a single multiplex PCR reaction. With this method we tested the DNA of the first cohort of 69 CF patients, a second cohort of $63 \mathrm{CF}$ patients, and 300 carrier relatives; we also performed 12 prenatal diagnoses. The results from the $132 \mathrm{CF}$ patients showed differences in the distribution of CF mutations between the south and north of Italy. The XV2c, KM19, and intron 8 VNDR haplotypes suggested the presence, in CF chromosomes bearing undetected mutations, of a limited number of unknown mutations typical of southern Italy. Finally, for six of the eight mutations, we compared the ASO procedure with the methods based on restriction enzymes; the results obtained with the two procedures were identical for all the 57 chromosomes compared.

( $($ Med Genet 1996;33:475-479)
\end{abstract}

Key words: cystic fibrosis; dot blot analysis; KM19; $\mathrm{XV} 2 \mathrm{c}$.

Cystic fibrosis (CF) is the most frequent hereditary disease in white populations, having an incidence of about 1 in $2500 .^{1}$ The disease is caused by molecular alterations in the cystic fibrosis transmembrane conductance regulator (CFTR) gene, identified in $1989 . .^{2-4}$ More than 500 CFTR mutations have been identified so far, ${ }^{5}$ most of which differ greatly in frequency depending on the ethnic group examined. The $\Delta$ F508 microdeletion accounts for about $75 \%$ of the CF mutations in most of the populations studied from northern Europe and America, ${ }^{1}$ but in southern Europe the incidence of the $\Delta F 508$ mutation in $C F$ chromosomes is below or around $50 \% .^{16}$ Thus, particularly in these populations, the first step in the molecular analysis of CF mutation bearing families is to select a panel of mutations, in addition to $\Delta F 508$, with which to maximise the percentage of CF chromosomes that can be characterised.

We studied a series of $264 \mathrm{CF}$ chromosomes from Campania and Basilicata (southern Italy, about $8 \times 10^{6}$ inhabitants), where no mutation other than $\Delta F 508$ had been previously studied, using an improved semiautomated procedure based on a single tube polymerase chain reaction (PCR) amplification followed by allele specific oligonucleotide (ASO) dot blotting. We found that (1) a panel of eight mutations (one of which is new for Italy) identified about $80 \%$ of CF chromosomes; (2) the method is rapid and efficient and the results are comparable with those obtained using restriction enzyme analysis; (3) the distribution of CF mutations in these regions is somewhat different from that of northern Italy; and (4) the analysis of the most used polymorphisms suggests the presence, in CF patients bearing unknown mutations, of a limited number of mutations typical of southern Italy.

\section{Materials and methods}

PATIENTS

Two cohorts of a total of $132 \mathrm{CF}$ patients were enrolled in the study. They were referred to us from the CF Regional Centres of Campania and Basilicata (southern Italy); the families of all patients were native to these regions for at least two previous generations. The diagnosis, made on clinical and anamnestic findings, was confirmed by the sweat test for chloride and sodium (cut off $60 \mathrm{mEq} / 1$ for both). The first cohort, which consisted of 69 CF patients, was analysed for the 22 CFTR mutations listed in table 1 using a semiautomatic allele specific oligonucleotide (ASO) procedure ${ }^{78}$ and for the $2183 \mathrm{AA} \rightarrow \mathrm{G}$ mutation using the restriction generating (RG) polymerase chain reaction (PCR) method. ${ }^{9}$ The analysis was performed twice on each sample in two different laboratories using a double blind procedure in all cases. The second cohort consisted of $63 \mathrm{CF}$ patients; they were analysed for the panel of eight mutations $(\Delta \mathrm{F} 508, \mathrm{~N} 1303 \mathrm{~K}, \mathrm{G} 542 \mathrm{X}$, R553X, 1717-1 G $\rightarrow$ A, W1282X, 1148T, and $2183 \mathrm{AA} \rightarrow \mathrm{G})$ previously identified in the first cohort, with the improved ASO method based 
Table 1 Mutations tested on DNA from 138 chromosomes of CF subjects from Campania and Lucania (southern Italy)

\begin{tabular}{ll}
\hline CFTR region & Mutations \\
\hline Multiplex 1 & \\
Exon 4 & $\mathrm{R} 117 \mathrm{H}, \mathrm{Y} 122 \mathrm{X}, \mathrm{I} 148 \mathrm{~T}$ \\
Intron 4 & $621+1 \mathrm{G} \rightarrow \mathrm{T}$ \\
Exon 10 & $\mathrm{Q} 493 \mathrm{X}, \Delta \mathrm{I} 507, \Delta \mathrm{F} 508$ \\
Intron 10 & $1717-1 \mathrm{G} \rightarrow \mathrm{A}$ \\
Exon 11 & $\mathrm{G} 542 \mathrm{X}, \mathrm{G} 551 \mathrm{D}, \mathrm{R} 553 \mathrm{X}, \mathrm{R} 560 \mathrm{~T}$ \\
Intron 19 & $3849+10 \mathrm{~Kb} \mathrm{C} \rightarrow \mathrm{T}$ \\
Exon 20 & $\mathrm{W} 1282 \mathrm{X}$ \\
& \\
Multiplex 2 & $\mathrm{G} 314 \mathrm{E}, 1078 \Delta \mathrm{T}, \mathrm{R} 334 \mathrm{~W}, \mathrm{R} 347 \mathrm{P}$ \\
Exon 7 & $\mathrm{A} 455 \mathrm{E}$ \\
Exon 9 & $\mathrm{R} 1162 \mathrm{X}, 3659 \Delta \mathrm{C}$ \\
Exon 19 & $\mathrm{N} 1303 \mathrm{~K}$ \\
Exon 21 & \\
\hline
\end{tabular}

on a single PCR amplification described below. All the chromosomes positive for W1282X, N1303K, G542X, 1717-1 A $\rightarrow$ G, 2183 $\mathrm{AA} \rightarrow \mathrm{G}$, and $\mathrm{R} 553 \mathrm{X}$ were also analysed with the restriction enzyme methodology.

\section{ASO ANALYSIS}

DNA was extracted from peripheral blood with the classical phenol/chloroform protocol. ${ }^{10}$ The semiautomated allele specific oligonucleotide (ASO) dot blot procedure used to detect the 22 CFTR gene mutations in the first cohort of CF patients has been described elsewhere. ${ }^{78}$ The improved method for the detection of the eight CF mutations in the second cohort of samples, included the following changes. (1) A single multiplex PCR reaction was used, with the following PCR conditions: $95^{\circ}$ for five minutes, 10 cycles at $94^{\circ}$ for 30 seconds, $65^{\circ}$ for 30 seconds, and $72^{\circ}$ for 30 seconds (decreasing the annealing temperature $1^{\circ}$ per cycle); 30 cycles at $94^{\circ}$ for 30 seconds, $60^{\circ}$ for 30 seconds, and $72^{\circ}$ for 30 seconds, and finally $70^{\circ}$ for five minutes. The amplimers described by Bozon et $a l^{9}$ were used for the $2183 \mathrm{AA} \rightarrow \mathrm{G}$ mutation. (2) The oligonucleotides used for the ASO analysis of the $2183 \mathrm{AA} \rightarrow \mathrm{G}$ mutation were: normal probe: 5'-CTTTGTTTTTTTGTTAGA; mutant probe: 5'-GAAACAAAAAGCAATCT. (3) The washing temperature for the $2183 \mathrm{AA} \rightarrow \mathrm{G}$ analysis was $42^{\circ} \mathrm{C}$.

\section{ANALYSIS OF CF POLYMORPHISMS}

The XV2c polymorphism was analysed by PCR amplification and enzyme incubation with Taq $\mathrm{I}^{11}$ using the following modified amplification conditions: $95^{\circ}$ for four minutes, 30 cycles at $94^{\circ}$ for 30 seconds, $52^{\circ}$ for 15 seconds and $70^{\circ}$ for 45 seconds, and finally $70^{\circ}$ for five minutes. The KM19 polymorphism was also detected by PCR amplification and enzymatic digestion with Pst ${ }^{12}$ The modified amplification conditions were: $94^{\circ}$ for five minutes, then 26 cycles at $94^{\circ}$ for 30 seconds, $55^{\circ}$ for 15 seconds, and $70^{\circ}$ for 45 seconds, and finally $65^{\circ}$ for five minutes. The intron 8 VNDR was detected using a modified PCR amplification with the following conditions: $95^{\circ}$ for five minutes, 30 cycles at $94^{\circ}$ for 15 seconds,

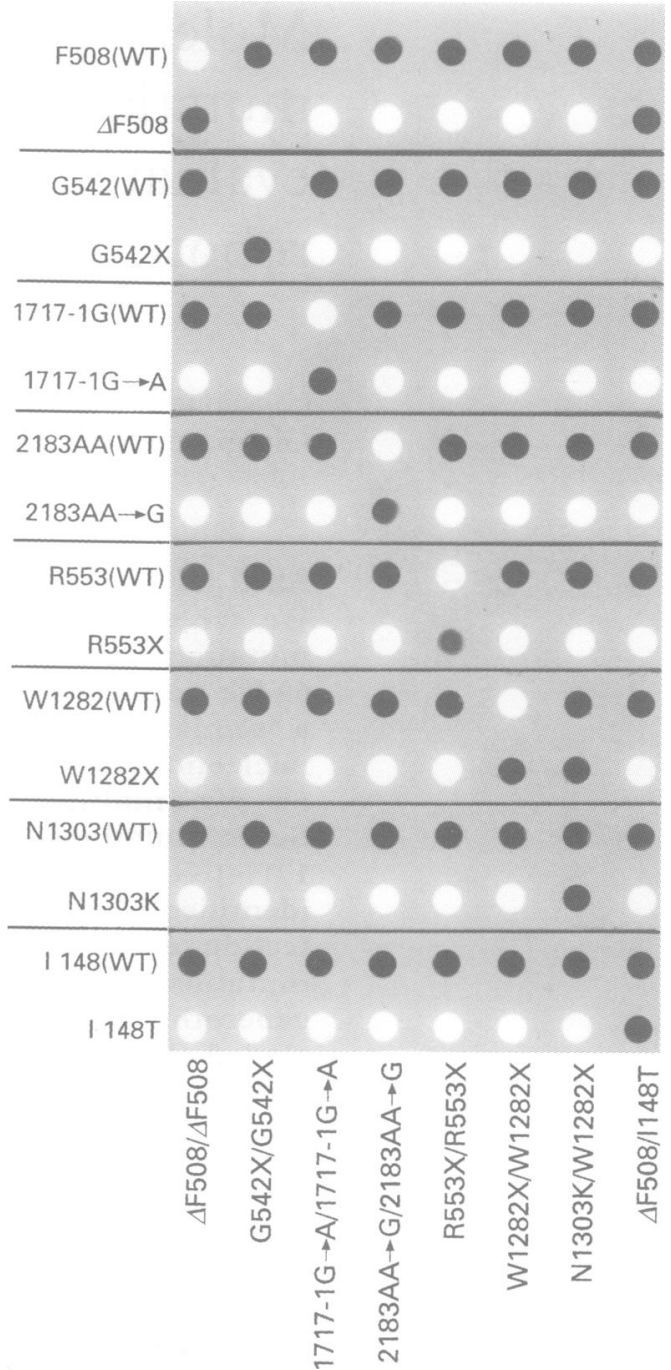

Figure 1 Eight $C F$ mutations in eight $C F$ patients bearing different genotypes, analysed with the improved allele specific oligonucleotide procedure. The genotypes are indicated at the bottom; on the left are indicated the mutations searched for, each with the wild type and mutated oligonucleotide.

$50^{\circ}$ for 15 seconds, and $65^{\circ}$ for 45 seconds, and finally, $70^{\circ}$ for five minutes, followed by polyacrylamide gel electrophoresis. ${ }^{13}$ For both XV2c and KM19, the haplotype numbering corresponds to the absence (allele 1) or presence (allele 2) of the restriction sites, and to the number of GT repeats for the intron 8 VNDR.

ANALYSIS OF CF MUTATIONS BASED ON RESTRICTION ENZYMES

The R553X mutation was analysed by digestion of the amplified product with the enzyme HincII, ${ }^{14} \mathrm{~W} 1282 \mathrm{X}$ using the restriction enzyme $M n l{ }^{15}$ the $1717-1 \mathrm{G} \rightarrow \mathrm{A}$ mutation by PCR mediated site directed mutagenesis followed by digestion with AvaII, ${ }^{16}$ and the G542X and the N1303K mutations were analysed by the restriction site generating PCR followed by digestion with $S c r F I$ and DdeI, respectively. ${ }^{17}$ The $2183 \mathrm{AA} \rightarrow \mathrm{G}$ mutation was analysed by RG-PCR followed by digestion with AluII. ${ }^{9}$ 
A

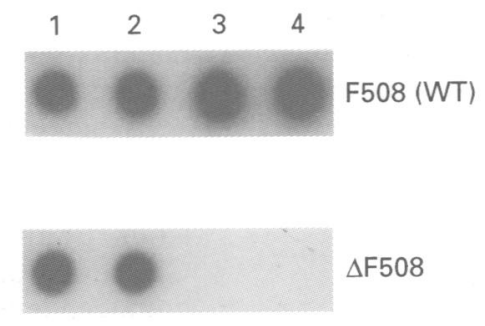

B
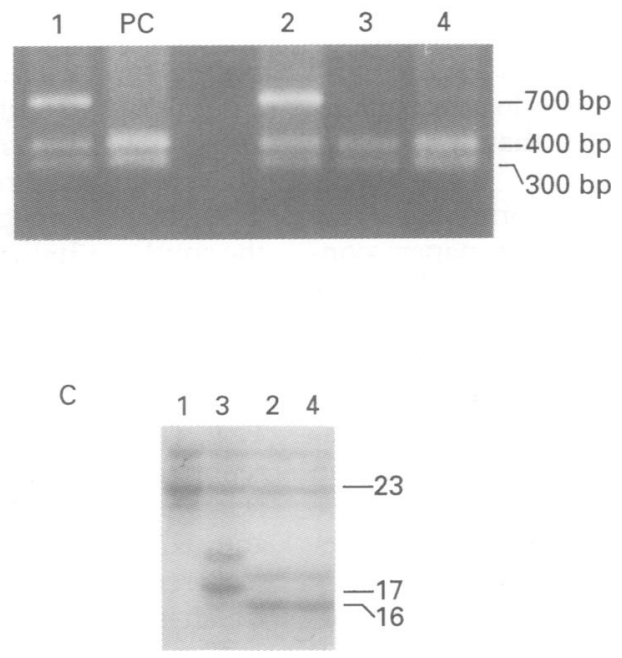

Figure 2 Prenatal diagnosis of $C F$ by direct $A S O$ analysis (panel $A$ ), by $X V 2 c$ polymorphism analysis (panel B), and analysis of intron $8 V N D R$ (panel $C$ ). $1=$ Child affected by CF; $2=$ father of $1 ; 3=$ mother of 1 ; $4=$ proband (chorionic villi from 3 ); $P C=$ positive control for TaqI digestion. The ASO analysis excluded, in the index case, the presence of $\triangle F 508$ (panel $A$ ), XV2c analysis did not exclude or confirm, in the index case, the presence of the unknown mutation of maternal origin (panel B). Intron $8 V N D R$ analysis in the proband showed the presence of the unknown mutation of maternal origin and thus the carrier state for CF (panel C).

\section{Results}

The $69 \mathrm{CF}$ patients in the first cohort were tested twice in double blind conditions by two different operators in two different laboratories (Houston and Naples) and the results obtained were identical. Seven of the 22 tested mutations were identified in the 69 patients tested. The seven mutations identified $77.6 \%$ of the $\mathrm{CF}$ chromosomes compared to $58 \cdot 7 \%$ when the
Table 2 Frequency of eight cystic fibrosis (CF) mutations in 264 CF chromosomes of patients from Campania and Basilicata (southern Italy)

\begin{tabular}{lrrl}
\hline Mutation & \multicolumn{2}{l}{$C F$ chromosomes } & $\begin{array}{l}\text { Cumulative } \\
\text { frequency (\%) }\end{array}$ \\
\cline { 2 - 3 } & \multicolumn{1}{l}{ No } & \multicolumn{1}{c}{$\%$} & \\
\hline$\Delta$ F508 & $149 / 264$ & $56 \cdot 4$ & $56 \cdot 4$ \\
N1303K & $18 / 264$ & $6 \cdot 8$ & $63 \cdot 2$ \\
G542X & $15 / 264$ & $5 \cdot 7$ & $68 \cdot 9$ \\
W1282X & $10 / 264$ & $3 \cdot 8$ & $72 \cdot 7$ \\
1717-1 G $\rightarrow \mathrm{A}$ & $6 / 264$ & $2 \cdot 3$ & $75 \cdot 0$ \\
$2183 \mathrm{AA} \rightarrow \mathrm{G}$ & $5 / 264$ & $1 \cdot 9$ & $76 \cdot 9$ \\
R553X & $3 / 264$ & $1 \cdot 1$ & $78 \cdot 0$ \\
I148T & $2 / 264$ & $0 \cdot 7$ & $78 \cdot 7$ \\
Undetected & $56 / 264$ & $21 \cdot 3$ & \\
\hline
\end{tabular}

screening was performed only for $\Delta \mathrm{F} 508$. The analysis of the $2183 \mathrm{AA} \rightarrow \mathrm{G}$ mutation increased the detection rate to $79 \cdot 8 \%$.

Fig 1 shows the results of the improved ASO analysis (see Materials and methods) of the eight mutations in eight CF patients bearing different genotypes. Also in this case the results are clear and no cross interference from the different mutations was identified. With this procedure, in addition to the $132 \mathrm{CF}$ patients, we also analysed about $300 \mathrm{CF}$ carriers and 12 samples of chorionic villi for prenatal diagnoses. In all instances the results were clear and unambiguous (fig 2).

The panel of eight mutations detected about $78.7 \%$ of CF chromosomes in our sample of $264 \mathrm{CF}$ chromosomes (table 2) compared to $56.4 \%$ when the screening was performed only for $\Delta F 508$. Table 3 shows the XV2c, KM19, and intron 8 VNDR haplotypes associated with each mutation; the haplotype was not established in a few (about 10\%) chromosomes. Most of the chromosomes bearing one of the eight mutations show haplotype 1 and 2 for $\mathrm{XV} 2 \mathrm{c}$ and KM19, respectively. These haplotypes are associated with allele 23 (or 17 in a small percentage of cases) for the intron 8 VNDR. However, the majority of CF chromosomes bearing an undetected mutation shows allele 16 on the intron 8 VNDR, which in our population is usually associated with non-CF chromosomes (table 2, last line). Three haplotypes, different from those associated with the eight detected mutations, are expressed by about $70 \%$ of CF chromosomes bearing unknown mutations. The 57 chromosomes bearing one of the following mut-

Table 3 Number of haplotypes typed in chromosomes associated with the eight mutations identified in CF patients from southern Italy. Typing is made on the basis of the following three polymorphisms: XV2c (1 or 2), KM19 (1 or 2), and intron 8 VNDR (from 16 to 25)

\begin{tabular}{|c|c|c|c|c|c|c|c|c|c|c|}
\hline $\begin{array}{l}\text { Haplotype } \\
\text { typing }\end{array}$ & $\Delta F 508$ & N1303K & $G 542 X$ & $W 1282 X$ & $\underbrace{1717-1}_{G \rightarrow A}$ & $I 148 T$ & $R 553 X$ & $\begin{array}{l}2183 \\
A A \rightarrow G\end{array}$ & $\begin{array}{l}\text { Unknown } \\
\text { mutation }\end{array}$ & $\begin{array}{l}\text { Normal } \\
\text { subjects }\end{array}$ \\
\hline $2,2,16$ & 0 & 0 & 0 & 0 & 0 & 0 & 0 & 0 & 1 & 0 \\
\hline $1,1,16$ & 0 & 0 & 0 & 0 & 0 & 0 & 2 & 0 & 8 & 7 \\
\hline $1,2,16$ & 1 & 0 & 0 & 0 & 6 & 0 & 0 & 5 & 7 & 2 \\
\hline $2,1,16$ & 0 & 0 & 0 & 0 & 0 & 0 & 0 & 0 & 16 & 11 \\
\hline $1,2,17$ & 27 & 0 & 0 & 9 & 0 & 0 & 0 & 0 & 0 & 1 \\
\hline $1,1,17$ & 1 & 0 & 0 & 0 & 0 & 0 & 0 & 0 & 2 & 6 \\
\hline $2,2,17$ & 1 & 0 & 0 & 0 & 0 & 0 & 0 & 0 & 1 & 2 \\
\hline $1,1,18$ & 0 & 0 & 0 & 0 & 0 & 0 & 1 & 0 & 0 & 0 \\
\hline $2,2,21$ & 0 & 1 & 0 & 0 & 0 & 0 & 0 & 0 & 0 & 0 \\
\hline $1,2,21$ & 3 & 0 & 0 & 0 & 0 & 0 & 0 & 0 & 0 & 0 \\
\hline $1,1,23$ & 0 & 1 & 0 & 0 & 0 & 0 & 0 & 0 & 0 & 0 \\
\hline $2,2,23$ & 9 & 0 & 0 & 0 & 0 & 0 & 0 & 0 & 3 & 0 \\
\hline $2,1,23$ & 0 & 0 & 0 & 0 & 0 & 0 & 0 & 0 & 4 & 0 \\
\hline $1,2,23$ & 84 & 14 & 13 & 0 & 0 & 2 & 0 & 0 & 2 & 0 \\
\hline $1,2,24$ & 2 & 1 & 0 & 0 & 0 & 0 & 0 & 0 & 0 & 0 \\
\hline $1,2,25$ & 1 & 0 & 0 & 0 & 0 & 0 & 0 & 0 & 0 & 0 \\
\hline Not defined & 20 & 1 & 2 & 1 & 0 & 0 & 0 & 0 & 12 & 0 \\
\hline
\end{tabular}


ations, N1303K, G542X, W1282X, R553X, $2183 \mathrm{AA} \rightarrow \mathrm{G}$, or 1717-1 A $\rightarrow \mathrm{G}$, were also analysed with restriction enzyme techniques. The results obtained with this technique totally matched those obtained with our improved ASO procedure.

\section{Discussion}

We describe an improved ASO method and the results of the molecular analysis of CF patients from Campania and Basilicata (southern Italy), previously analysed in part only for the $\Delta \mathrm{F} 508$ mutation. ${ }^{6}$ This study confirms the efficiency of the ASO dot blot procedure, and our double blind analysis, performed on the first cohort of cases, shows that it is highly reproducible and robust.

The changes to the original ASO methodology ${ }^{78}$ described in this paper, consisting of the use of a single multiplex PCR and the ASO procedure for eight mutations including $2183 \mathrm{AA} \rightarrow \mathrm{G}$, allow more rapid detection of the eight most frequent mutations in southern Italy. With this method, as many as 96 DNA samples can be tested in a single run and identical results were obtained when we analysed six of these mutations with the restriction enzyme based methodology.

The molecular analysis of the study population of $\mathrm{CF}$ patients from southern Italy showed that the eight mutations screened account for $79 \%$ of CF chromosomes; this result shows higher genetic homogeneity for mutations in CF patients from southern Italy than in those from northern Italy, where screening for 62 mutations identified about $74 \%$ of $\mathrm{CF}$ chromosomes bearing 14 known mutations. ${ }^{18}$ The incidence of $\Delta \mathrm{F} 508$ in our population on the basis of $264 \mathrm{CF}$ chromosomes is $56.4 \%$, slightly higher than that (about $50 \%$ ) previously reported, ${ }^{6}$ but much lower than that in northern Europe. ${ }^{1}$ The frequency of the G542X mutation is higher in our regions of southern Italy than in northern Italy $(5 \cdot 7 \%$ versus $2 \cdot 6 \%) .{ }^{18}$ The high frequency of $\mathrm{G} 542 \mathrm{X}$ in our regions could result from the spreading of the mutation along Mediterranean coastal areas by the Arabs or from the Spanish domination of southern Italy for several centuries ${ }^{19}$; indeed, G542X is the second most frequent mutation in Spanish Mediterranean coastal areas. ${ }^{19}$ One of the G542X bearing subjects, who was homozygous for this mutation, was the first case ever among seven showing very severe liver involvement (Castaldo et al, personal communication).

The R1162X mutation, which is the second most frequent mutation (about $10 \%$ ) in northern Italy, was absent from our population, and the $2183 \mathrm{AA} \rightarrow \mathrm{G}$, which is present in about $10 \%$ of CF patients from northern Italy, ${ }^{20}$ had a much lower frequency (about $2 \%$ ) in our CF population. These findings confirm that there are differences in the genetic background between southern and northern Italy. In addition, we found the first two Italian cases of the rare I148T mutation, recently reported in $0.1 \%$ of French ${ }^{21}$ and in $9 \cdot 1 \%$ of French Canadian ${ }^{5}$ $\mathrm{CF}$ patients, in two patients with compound heterozygosity for $\Delta \mathrm{F} 508$; the mutation has never been reported previously in Italy. These patients had very severe pancreatic and lung disease. $^{22}$

In agreement with previous results, ${ }^{23}$ the analysis of the polymorphisms associated with the CFTR gene showed that in the CF population from southern Italy the most frequent CF mutations are usually associated with homogeneous haplotypes, that is, allele 1 for XV2c, allele 2 for KM19, and allele 23 or, less frequently, allele 17 for the intron 8 VNDR. The $\Delta \mathrm{F} 508$ mutation is frequently associated with haplotype 1, 2, 23, (XV2c, KM19, and intron 8 VNDR, respectively) and, in a small percentage of cases, with haplotype $1,2,17$. The G542X mutation was associated with haplotype 1,2, 23 and this reinforces the notion of the common origin of the mutation and the close ethnic and genetic relationship between the southern Italian and Spanish populations. ${ }^{19}$ Of the three chromosomes bearing the R553X mutation, one is associated with haplotype 1 , 1,18 for the three polymorphisms respectively; the other two homozygously show haplotype $1,1,16$. These findings, together with earlier reports describing the association of this mutation with both alleles 1 and 2 for both XV2c and KM19 polymorphisms, ${ }^{24-26}$ confirm the recurrent origin of the $\mathrm{R} 553 \mathrm{X}$ mutation, ${ }^{27}$ which is located in a hypervariable $\mathrm{CpG}$ region.

The haplotype patterns of $1717-1 \mathrm{G} \rightarrow \mathrm{A}$ and W1282X were homogeneous (table 3 ), which is in agreement with previous data. ${ }^{24}$ For N1303K all but two chromosomes showed the intron 8 VNDR allele 23, while one single chromosome carried allele 21 and another allele 24 ; other polymorphisms will be analysed to define whether they could derive from the most frequent variant 23 . Finally, all the five $C F$ chromosomes bearing the $2183 \mathrm{AA} \rightarrow \mathrm{G}$ mutation showed haplotype $1,2,16$ and the two I148T chromosomes were associated with the $1,2,23$ haplotype. This is the first report of the haplotype pattern for chromosomes bearing these mutations.

In our sample of patients, most of the CF chromosomes with unidentified mutations showed the three most frequent haplotype patterns, in which alleles 1 and 2 (for either XV2c or KM19) are always associated with allele 16 of the intron $8 \mathrm{VNDR}$, which is the most frequent allele in non-CF chromosomes. These results suggest that a limited number of unknown mutations might be present with a high frequency in a large percentage of CF chromosomes bearing unknown mutations from our region; we are now screening to try to unravel the nature of these mutations by DGGE and sequencing analysis. This observation is in agreement with studies conducted in other Italian regions on the T338I mutation, which is peculiar to the Sardinian CF population, ${ }^{28}$ on $2183 \mathrm{AA} \rightarrow \mathrm{G},{ }^{20}$ and on $\mathrm{R} 1162 \mathrm{X},{ }^{1820}$ both of which are very frequent in some areas of northern Italy. However, in other geographical areas such as Spain ${ }^{29}$ and Germany ${ }^{30}$ the analysis of the polymorphisms associated with the CFTR gene suggest that there are probably more than 100 different unidentified mutations. Furthermore, in our population the high 
frequency of the intron 8 VNDR allele 16 among CF chromosomes bearing unknown mutations and among non-CF chromosomes indicates that no linkage disequilibrium exists between intron 8 VNDR haplotypes and normal or CF chromosomes.

In conclusion, our results confirm the excellent analytical performance of the improved semiautomated robotised ASO dot blot procedure for the analysis of CF mutations. We suggest the semiautomated ASO technique be used if panels of mutations and large series of samples are analysed, whereas the methods based on restriction analysis are more suitable for the study of single cases in families bearing known CF mutations. In addition, the most frequent CF mutations in patients from southern Italy are different from those found in northern Italy, and our analysis may also suggest the presence of a limited number of undetected mutations peculiar to our geographical area. These results have an impact on other populations, given the migration of quite large groups of people from southern Italy in the last 200 years, and the consequent genetic mixing, particularly in northern Italy, Switzerland, Germany, and the United States.

We thank Dr Sue Richards (Baylor College of Medicine, Houston, Texas), in whose laboratory this work was initiated, for her support and advice. Grants from MURST, Regione Campania, AGENSUD, CNR (PF Biotecnologie), and Ministero della Sanità (Rome) are gratefully acknowledged.

1 Romeo G, Devoto M. Population analysis of the major mutation in cystic fibrosis. Hum Genet 1990;85:391-445. mutation in cystic fibrosis. Hum Genet 1990;85:391-445.
Rommens JM, Iannuzzi MC, Kerem BS, et al. Identification of the cystic fibrosis gene: chromosome walking and jump-
of ing. Science 1989;245:1059-65.

3 Riordan JR, Rommens JM, Kerem BS, et al. Identification of the cystic fibrosis gene: cloning and characterization of complementary DNA. Science 1989;245:1066-73.

4 Kerem BS, Rommens JM, Buchanan JA, et al. Identification of the cystic fibrosis gene: genetic analysis. Science 1989 245:1073-80.

5 The Cystic Fibrosis Genetic Analysis Consortium. Population variation of common cystic fibrosis mutations. Hum Mutat 1994;4:167-77.

6 Santamaria F, Salvatore D, Castiglione O, Raia V, De Ritis $G$, Sebastio $G$. Lung involvement, the $\Delta$ F508 mutation and DNA haplotype analysis in cystic fibrosis. Hum Genet and DNA haplotype

7 De Marchi JM, Beaudet AL, Caskey CT, Richards CS. Experience of an academic reference laboratory using automation for analysis of cystic fibrosis mutations. Arch Pathol Lab Med 1994;118:26-32.

8 De Marchi JM, Richards CS, Fenwick RG, Pace R, Beaudet AL. A robotic-assisted procedure for large scale cystic fibrosis mutation analysis. Hum Mutat 1994;4:281-90. of four new mutations in the CFTR gene: I148T, L1077P, $\mathrm{Y} 1092 \mathrm{X}, 2183 \mathrm{AA} \rightarrow \mathrm{G}$. Hum Mutat 1994;3:330-2.

10 Sambrook J, Fritsch EF, Maniatis T. Molecular cloning: a laboratory manual. 2nd ed. New York: Cold Spring Harbor Laboratory Press, 1989.

11 Rosenbloom CL, Kerem BS, Rommens JM, et al. DNA amplification for detection of the XV-2c polymorphism linked to cystic fibrosis. Nucleic Acids Res 1989;17:7117.

12 Feldman GL, Williamson R, Beaudet AL, O'Brien WE. Prenatal diagnosis of cystic fibrosis by DNA amplification for detection of KM 19 polymorphism. Lancet 1988;ii: 102.

13 Morral N, Nunes V, Casals T, Estivill X. CA/GT microsatellite alleles within the cystic fibrosis transmembrane conductance regulator (CFTR) gene are not generated by unequal crossingover. Genomics 1991;10:692-8.

14 Cutting GR, Kasch LM, Rosenstein BJ, et al. A cluster of cystic fibrosis mutations in the first nucleotide-binding fold of the cystic fibrosis conductance regulator protein. Nature 1990;346:366-9.

15 Vidaud M, Fanen P, Martin J, Ghanem N, Nicolas S, Goossens $M$. Three point mutations in the CFTR gene in French cystic fibrosis patients: identification by denaturing gradient gel electrophoresis. Hum Genet 1990;85:446-9.

16 Cremonesi L, Seia M, Magnani C, Ferrari M. Rapid detection of $1717-1 \mathrm{G} \rightarrow \mathrm{A}$ mutation in CFTR gene by PCR mediated site directed mutagenesis. Clin Chem 1991;37: 1967.

17 Gasparini P, Bonizzato A, Degnini M, Pignatti PF. Restriction site generating-polymerase chain reaction (RGPCR) for the probeless detection of hidden genetic variation: application to the study of some common cystic ation: application to the study of some comm

18 Gasparini P, Marigo C, Bisceglia G, et al. Screening of 62 mutations in a cohort of cystic fibrosis patients from
north eastern Italy: their incidence and clinical features of north eastern Italy: their incidence and clinical fe
defined genotypes. Hum Mutat 1993;2:389-94.

19 Casals T, Nunes V, Palacio A, et al. Cystic fibrosis in Spain: high frequency of mutation G542X in the Mediterranean coastal area. Hum Genet 1993;91:66-70.

20 Bonizzato A, Bisceglie L, Marigo C, et al. Analysis of the complete coding region of the CFTR gene in a cohort of CF patients from north-eastern Italy: identification of $90 \%$ of the mutations. Hum Genet 1995;95:397-402.

21 Chevalier-Porst F, Bonardot AM, Gilly R, Chazalette JP, Mathieu M, Bozon D. Mutation analysis in 600 French cystic fibrosis patients. $\mathcal{F}$ Med Genet 1994;31:541-4.

22 Castaldo G, Rippa E, Raia V, et al. Clinical features of cystic fibrosis patients with rare genotypes. $f$ Med Genet 1996; 33:73-6.

23 Morral N, Bertranpetit J, Estivill X, et al. The origin of the major cystic fibrosis mutation $(\Delta \mathrm{F} 508)$ in European the major cystic fibrosis mutation $(\Delta \mathrm{F} 508)$

24 Dork T, Neumann T, Wulbrand U, et al. Intra- and extragenic marker haplotypes of CFTR mutations in cystic fibrosis families. Hum Genet 1992;88:417-25.

25 Bal J, Stuhrmann M, Schloesser M, Schmidtke J, Reiss J. A cystic fibrosis patient homozygous for the nonsense mutation R553X. F Med Genet 1991;28:715-17

26 Cheadle J, Al-Jader L, Goodchild M, Meredith AL. Mild pulmonary disease in a cystic fibrosis child homozygous for R553X. I Med Genet 1992;29:597.

27 Reiss J, Cooper DN, Bal J, Slomski R, Cutting GR, Krawczak $M$. Discrimination between recurrent mutation and identity by descent: application to point mutations in exon 11 of the cystic fibrosis (CFTR) gene. Hum Genet 1991; 87:457-61.

28 Rendine S, Piazza A. Genetic history of CF mutations in Italy. 20th European Cystic Fibrosis Conference, Bruxelles, 1995: Abst P204.

29 Chillon M, Casals T, Gimenez J, et al. Analysis of the CFTR gene confirms the high genetic heterogeneity of the Spanish population: 43 mutations account for only $78 \%$ of CF chromosomes. Hum Genet 1994;93:447-51.

30 Dork T, Mekus F, Schmidt K, et al. Detection of more than 50 different CFTR mutations in a large group of German cystic fibrosis patients. Hum Genet 1994;94:533-42. 